IRSTI 34.49 .23

https://doi.org/10.26577/phst.2021.v8.i2.01

\title{
Estimated measurements of natural background radiation in the surface atmospheric layer of the Almaty region
}

\author{
V.V. Dyachkov* iD, M.T. Bigeldiyeva iD, Yu.A. Zaripova iD and A.V. Yushkov iD \\ Al-Farabi Kazakh National University, Almaty, Kazakhstan \\ e-mail:*Inirp206@gmail.com
}

\begin{abstract}
The radon isotopes of natural radioactive radiation of the earth's crust emanating to the surface are concentrated in the human environment and have a direct impact on the people health. Due to this fact the problem of studying the radiation distributions in the surface atmospheric layer of the Earth is urgent. In this work, measurements of the exposure dose rate, beta particle flux, and equivalent equilibrium volumetric activity (EEVA) of radon in the surface atmospheric layer of the Earth have been performed. Measurements of radon and gamma, beta backgrounds were carried out from April 2021 to August 2021 in the Almaty region at various altitudes above sea level: from 500 to 2500 meters. They were carried out using electronic radiometric equipment: beta-dosimeter "RKS-01B-SOLO"; gamma dosimeter "RKS-01GSOLO"; radiometer of radon-222 "RAMON-02" in the field. As a result, preliminary assessment schemes were built for route measurements of the $222 \mathrm{Rn}$ radon isotope, beta and gamma radiation fields from natural daughter products of decay of radon isotopes and radionuclides located in the surface atmospheric layer. As a result of this work, an altitude dependence of changes in the natural radiation gamma and beta background of the surface surface layer is presented, which grows with an increase in the surface above sea level. The different activity of radon over rocks and soils is shown, which, as is known, is associated with the exhalation of radon and which depends, among other things, on the density of the soils. The preliminary results of measurements of significant perturbations of the EEVA of radon did not reveal.
\end{abstract}

Key words: variations in time of radon; natural beta active radionuclides; coagulation; atmospheric radioactive nanoparticles.

PACS number: 23.60 .

\section{Introduction}

The territory of Kazakhstan is characterized by a complex radiation situation due to the presence of active mine development of rich deposits of minerals, especially coal, non-ferrous metals and uranium, geological features, seismically active zones in the south and mountainous areas. Radon and its decay products, which are formed in natural radioactive chains, have a significant effect on the general background radiation among natural sources of ionizing radiation. The radionuclides formed during such decays, from the depths of the lithosphere, by coagulation and further diffusion, enter the surface atmospheric layer [1-4]. The contribution of radon to the average annual radiation dose from natural sources is more than $50 \%$. Due to the fact that radon isotopes are concentrated in the human environment and have a direct impact on the health of the population, the problem of studying the distributions of radon isotopes emanations in the surface atmospheric layer of the Earth remains relevant.

The concentration of radon and its daughter decay products (DDP) in the surface atmospheric layer is extremely uneven and depends on the geological and geophysical characteristics of the natural environment [5], in this regard, different countries use their own approaches to determining the radon hazard of the territory. At present, all countries are striving to carry out radiation-ecological measurements and research on the radon hazard, which are based on methods for mapping radon. So, in the countries of the European Union, the concept of «geogenic radon potential» is key in assessing the potential radon hazard of territories [6-9]. At the same time, in different countries, the concept is based on various factors: in Serbia - the content of natural radionuclide in the soil [10], in Norway - the correlation between indoor radon and geology [11], in Switzerland - the dose rate of gamma radiation, geology, lines faults, permeability of the upper soil layer [12]. 
The natural background radiation in the regions of Kazakhstan averages $3.1 \mathrm{mSv} /$ year [13]. And the total dose from natural and man-made sources of radiation on average per person in Kazakhstan is about $4 \mathrm{mSv} /$ year, which is one and a half times higher than the world average. The study of the spatial distribution of the emanation of radon isotopes in the foothill Almaty region of the Tien Shan is an urgent task, since tectonic faults and mountain fallows are additional sources of radiation of radon and its daughter decay products. The purpose of this study was to perform preliminary assessment measurements of the radiation hazard for the population exposed to alpha, beta, gamma radiation at the level of the surface atmospheric layer from the daytime surface of the Earth.

\section{Experimental procedure and methodology}

In this work, field measurements of gamma and beta radiation fields on the surface of the earth's layer were carried out and the concentration of radon in suspended aerosol particles in the surface atmospheric layer was measured. Methods for performing measurements were worked out according to [14-16] and optimized for the given field measurements. The difficulties in performing the experimental part of this work are related to the fact that measurements had to be carried out under certain meteorological conditions, since their influence rather strongly causes fluctuations in the exhalation of radon from the soil into the atmosphere [17]. In addition, carry out measurements during this season to avoid the influence of seasonal variations in the measured data [18-19]. The control points for measuring gamma-fan, beta-background and radon activity were chosen for reasons of minimal changes in external factors (depressions, pits of natural origin). Humidity and temperature were monitored at these points.

Measurements of the spatial distribution of radon isotopes were carried out from April 2021 to August 2021 with dry soil and stable meteorological conditions in the foothills of the Trans-Ili Alatau Tien Shan in the Almaty region at various altitudes above sea level: from 500 to 2500 meters. In connection with the developed comprehensive urban planning scheme for the territory of the Almaty region until 2045 , the study area was selected and located in the foothill Almaty region on an area of $4500 \mathrm{~km}^{2}$ : its coordinates are between $43.20-43.85^{\circ}$ north latitude and 76.32-77, $50^{\circ}$ east longitude. Measurements of the natural radiation near-surface layer of the earth were carried out using electronic radiometric equipment: a radiometer beta-dosimeter "RKS-01BSOLO"; gamma dosimeter "RKS-01G-SOLO"; concentration of radon in suspended aerosol particles in the surface atmospheric layer - with a radon radiometer "RAMON-02". All measurement results were performed with a statistical error not exceeding $10 \%$ (at each control point, from 3 to 5 measurements were carried out).

\section{Analysis of experimental data}

As a result of field measurements, preliminary estimation schemes of the route of control points for measuring gamma background, beta background (Fig. 1,2) and a scheme of the route of control points (Fig. 3) for measuring the equivalent equilibrium volumetric activity of radon (EEVA) were built. In Table 1, the geolocation coordinates of the positions of the control measuring points and the corresponding values of the beta-particles flux, the exposure dose rate (EDR) and the EEVA of radon, taking into account the instrumental error, for the RKS-01BSOLO beta dosimeter - $15 \%$; gamma dosimeter "RKS-01G-SOLO" - 12\% and radon radiometer "RAMON-02" - 30\%.

Figures 1-2 and 4-5 show that the altitude dependence of changes in the natural radiation gamma and beta background of the surface surface layer manifests itself quite well. Despite the local fluctuations of values from the general growing trend, this effect is confidently recorded. In addition to natural beta radionuclides of terrestrial origin, such as $40 \mathrm{~K}$ and $87 \mathrm{Rb}$, the DDP of radon isotopes, which are also the DDP of thorium, uranium-radium and uranium-actinium series of natural terrestrial chains of radioactive decay [20-22]. As you know, in the foothills of rocks, radon exhalation is low through dense rocks (not taking into account local cracks in rocks due to their inhomogeneous spatial distribution), and also, as you know, in porous soils, radon exhalation is high, which is indirectly, of course necessary. at the same time, making corrections for horizontal transfer, mixing of air masses of the surface layer is reflected in the scheme of the route of control points for measuring the EEVA of radon (Figure 3). Of course, the rate of dissolution and mixing in the surface atmospheric layer must be taken into account for future measurements. In this work, this parameter was taken into account qualitatively, by choosing a place for measurements. 


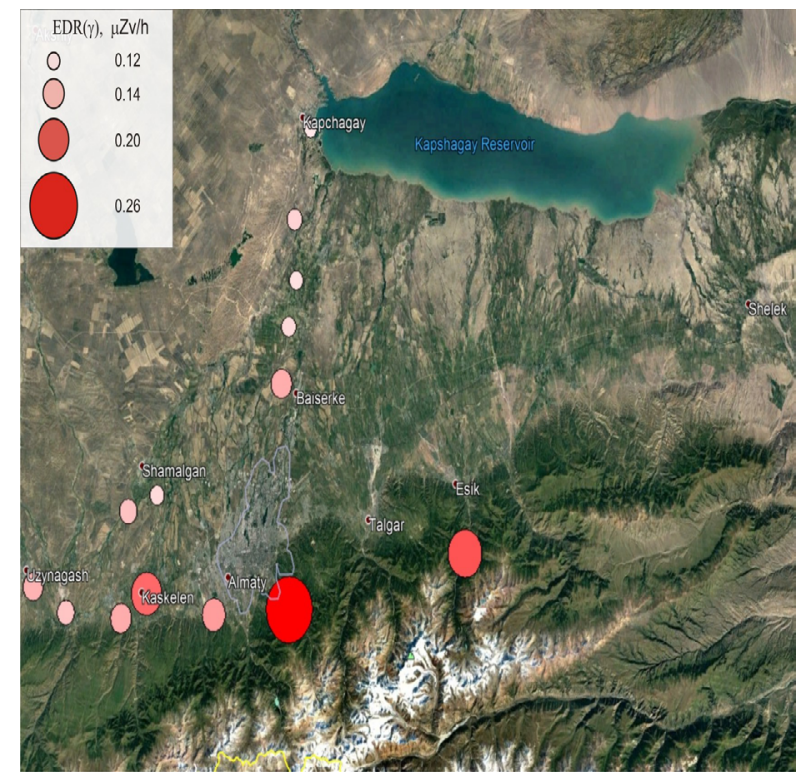

Figure 1 - Scheme of the route of control points for measuring the natural radiation gamma background of the surface layer.

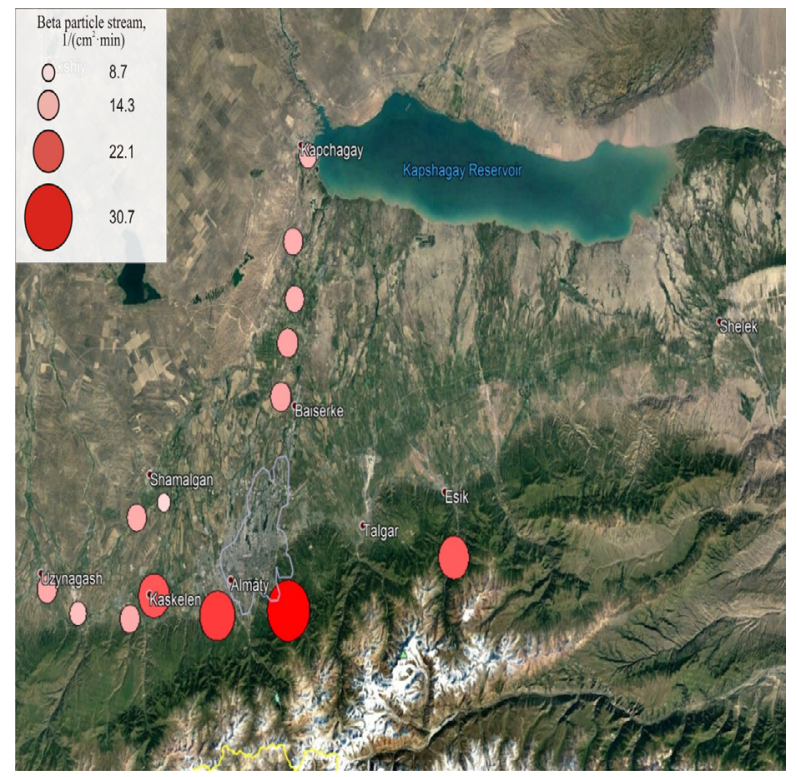

Figure 2 - Scheme of the route of control points for measuring the natural radiation beta background of the surface layer.

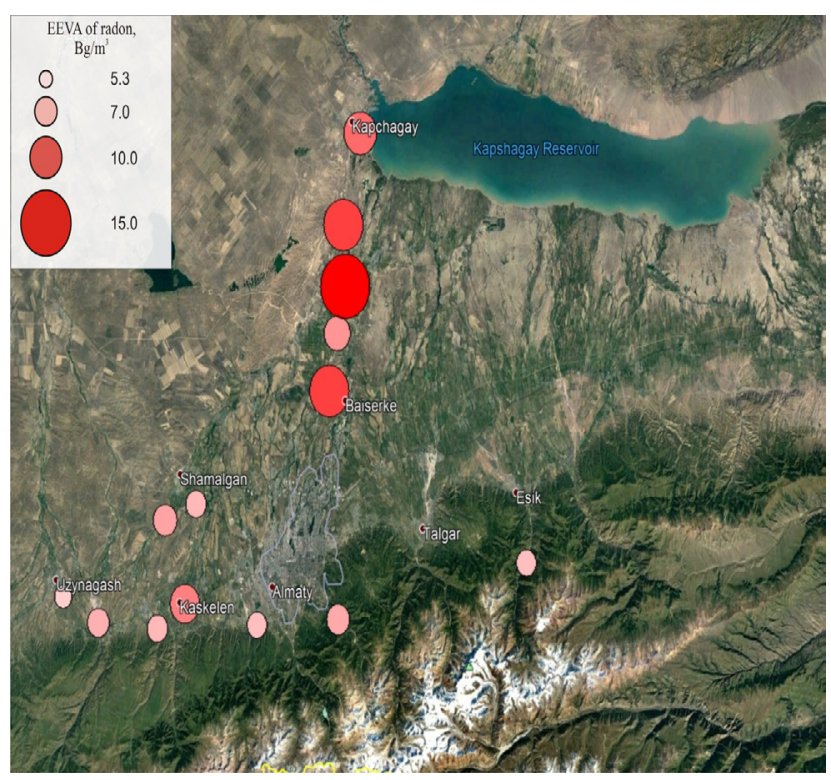

Figure 3 - Scheme of the route of control points for measuring the equivalent equilibrium volumetric activity of the $222 \mathrm{Rn}$ radon isotope.

Table 1 - The values of the geolocation coordinates of the positions of the control measuring points and the corresponding values of the flux of beta particles, EDR and EEVA of radon.

\begin{tabular}{|c|c|c|c|c|c|c|}
\hline Pos. & Latitude, degrees & $\begin{array}{c}\text { Longitude, } \\
\text { degrees }\end{array}$ & Altitude, $\mathrm{m}$ & $\operatorname{EDR}(\mathrm{g}$ & $\begin{array}{c}\text { Beta particle stream, 1/ } \\
\left(\mathrm{cm}^{2} \cdot \mathrm{min}\right)\end{array}$ & $\begin{array}{c}\mathrm{EEVA}\left(\boldsymbol{( 2 2}^{22} \mathrm{Rn}\right), \mathrm{Bq} / \\
\mathrm{m}^{3}\end{array}$ \\
\hline 1 & 43.1695000 & 76.8137100 & 1013 & $0.168 \pm 0.020$ & $25.0 \pm 3.7$ & $6.0 \pm 1.8$ \\
\hline 2 & 43.2552980 & 77.4836280 & 1722 & $0.211 \pm 0.025$ & $21.5 \pm 3.2$ & $6.0 \pm 1.8$ \\
\hline 3 & 43.1780920 & 77.0163810 & 1273 & $0.264 \pm 0.031$ & $30.7 \pm 4.6$ & $7.0 \pm 2.1$ \\
\hline
\end{tabular}


Table continuation

\begin{tabular}{|c|c|c|c|c|c|c|}
\hline Pos. & Latitude, degrees & $\begin{array}{c}\text { Longitude, } \\
\text { degrees }\end{array}$ & Altitude, $\mathrm{m}$ & EDR(g & $\begin{array}{c}\text { Beta particle stream, 1/ } \\
\left(\mathrm{cm}^{2} \cdot \mathrm{min}\right)\end{array}$ & $\begin{array}{c}\mathrm{EEVA}\left({ }^{222} \mathrm{Rn}\right), \mathrm{Bq} / \\
\mathrm{m}^{3}\end{array}$ \\
\hline 4 & 43.4930300 & 76.9939700 & 601 & $0.158 \pm 0.019$ & $14.2 \pm 2.1$ & $12.0 \pm 3.6$ \\
\hline 5 & 43.5728200 & 77.0136000 & 567 & $0.132 \pm 0.016$ & $14.3 \pm 2.1$ & $8.0 \pm 2.4$ \\
\hline 6 & 43.6378800 & 77.0337800 & 533 & $0.128 \pm 0.015$ & $13.0 \pm 1.9$ & $15.0 \pm 4.5$ \\
\hline 7 & 43.7232600 & 77.0293300 & 500 & $0.136 \pm 0.016$ & $13.2 \pm 2.0$ & $12.0 \pm 3.6$ \\
\hline 8 & 43.8507100 & 77.0722600 & 481 & $0.124 \pm 0.015$ & $12.1 \pm 1.8$ & $10.0 \pm 3.0$ \\
\hline 9 & 43.1983085 & 76.6333545 & 843 & $0.198 \pm 0.024$ & $22.1 \pm 3.3$ & $9.0 \pm 2.7$ \\
\hline 10 & 43.1639867 & 76.5653418 & 970 & $0.159 \pm 0.019$ & $13.4 \pm 2.0$ & $6.3 \pm 1.9$ \\
\hline 11 & 43.1711225 & 76.4172858 & 993 & $0.144 \pm 0.017$ & $11.4 \pm 1.7$ & $6.7 \pm 2.0$ \\
\hline 12 & 43.2065420 & 76.3282000 & 837 & $0.155 \pm 0.019$ & $13.7 \pm 2.1$ & $5.3 \pm 1.6$ \\
\hline 13 & 43.3135819 & 76.5831044 & 729 & $0.146 \pm 0.017$ & $13.3 \pm 2.0$ & $7.3 \pm 2.2$ \\
\hline 14 & 43.3363474 & 76.6603148 & 702 & $0.131 \pm 0.016$ & $8.7 \pm 1.3$ & $6.3 \pm 1.9$ \\
\hline
\end{tabular}

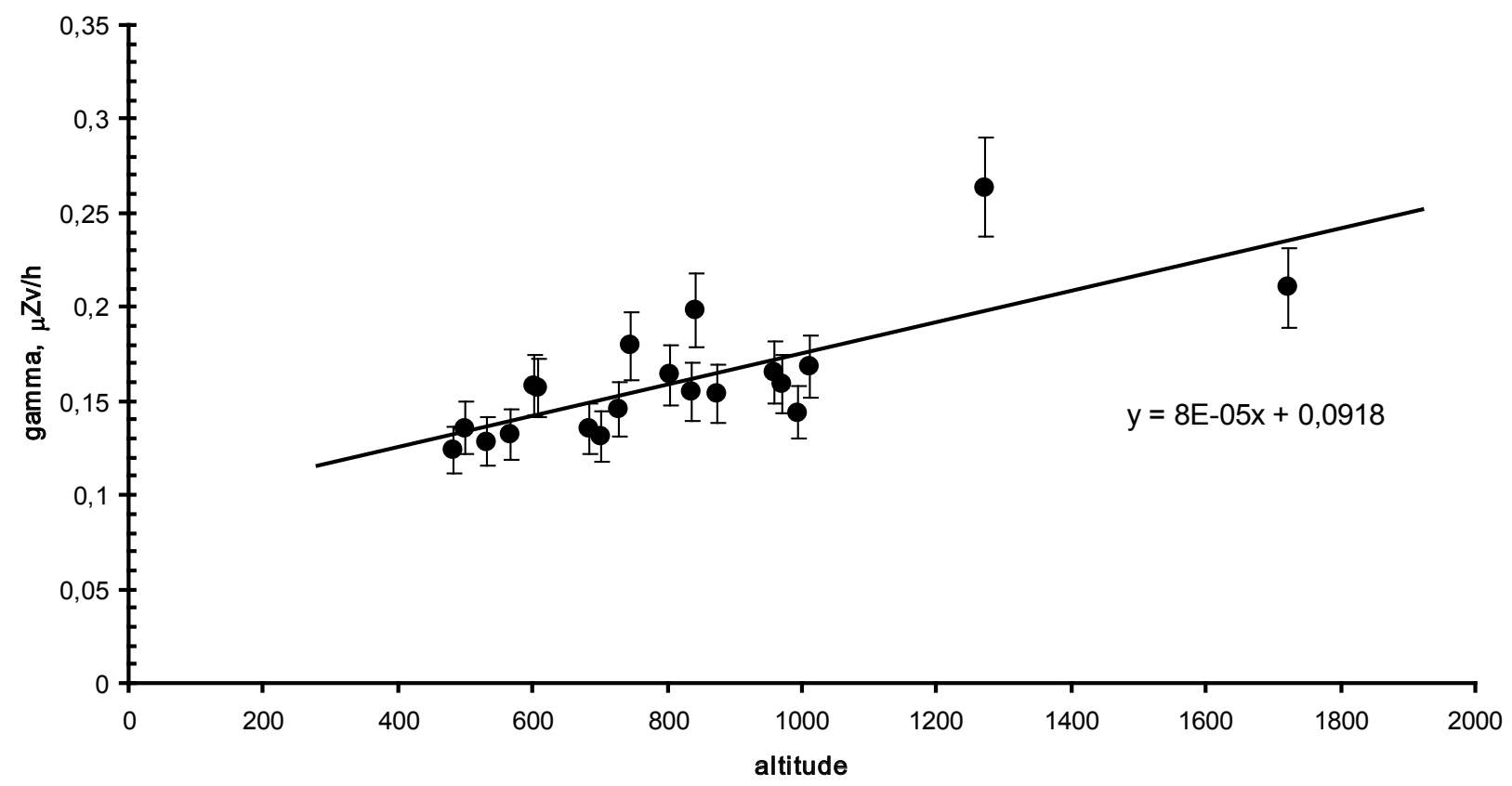

Figure 4 - Dependence of the natural radiation gamma background of the surface layer on the height above sea level (altitude).

In this work, the values of the beta background are in satisfactory agreement and correlate with the results of beta-spectrometry of samples of the surface layer of soil taken in different places in Almaty [2324]. EEVA of radon does not obey such a clear relationship. The concentration of radon in suspended aerosol particles in the surface atmospheric layer is quite sensitive to the local geological structure (groundwater, soil type and its porosity) and meteorological conditions. But, nevertheless, as expected, you can notice different radon activity over rocks and soils. The averaged values as a whole over the entire measurement range are in good agreement with the results obtained in [25]. 


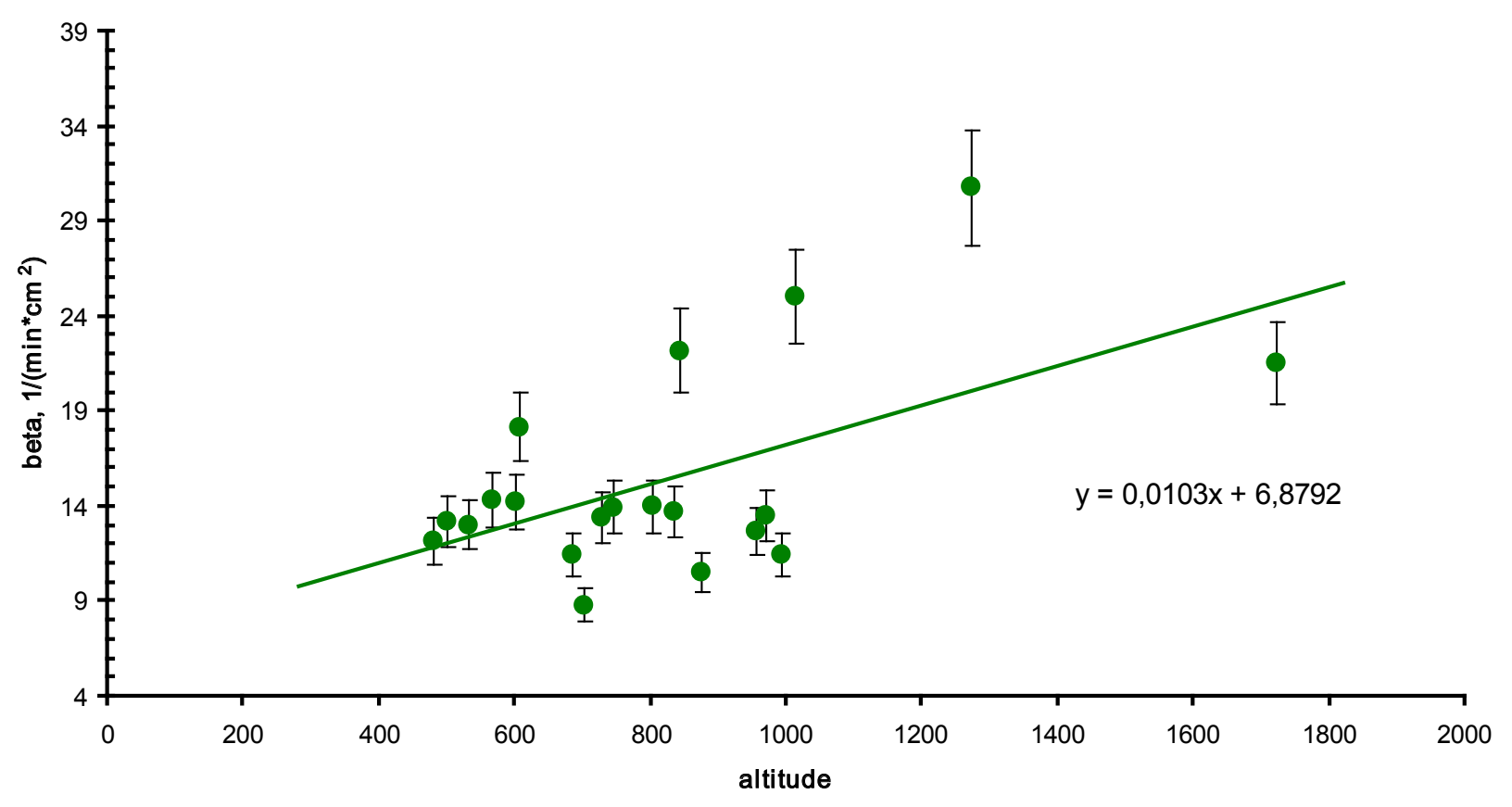

Figure 5 - Dependence of the natural radiation beta background of the surface layer on the height above sea level (altitude)

\section{Conclusions}

Thus, as a result of route measurements of gamma and beta radiation fields on the surface of the earth's layer and the concentration of radon in suspended aerosol particles in the surface atmospheric layer, preliminary estimation schemes of route measurements of the distribution of natural radiation gamma and beta background of the surface layer and a route measurement scheme were constructed distribution of the equivalent equilibrium volumetric activity of the radon isotope. An altitude dependence of changes in the natural radiation gamma and beta background of the surface layer is shown, which grows with an increase in the surface above sea level. The different activity of radon over rocks and soils is shown, which, as is known, is associated with the exhalation of radon and which depends, among other things, on the density of the soils. The preliminary results of measurements of significant perturbations of the EEVA of radon did not reveal.

\section{Aknowledgements}

This research is funded by the Science Committee of the Ministry of Education and Science of the Republic of Kazakhstan (Grant No. AP09258978).

\section{References}

1 V. S. Yakovleva, V. D. Karataev. Criteria for assessing the potential radon hazard of territories // Radiation biology. Radioecology -2004. -Vol. 44. -No.2 -Pp. 227-231 (in Russian).

2 V. S. Yakovleva, V. D. Karataev, A. V. Vukolov, I. I. Ippolitov, M. V. Kabanov, P. M. Nagorskiy, S. V. Smirnov, P. P. Firstov, R. I. Parovik. Methodology of a multifactorial experiment on radon transport processes in the "lithosphereatmosphere" system // ANRI. -2009. -No. 4. -Pp. 55-60 (in Russian).

3 P. M. Nagorskiy, I. I. Ippolitov, S. V. Smirnov, V. S. Yakovleva, V. D. Karataev, A. V. Vukolov, V. V. Zukau. Features of monitoring of radioactivity in the "lithosphere-atmosphere" system by $\beta$ - and $\gamma$-radiation // Izvestiya VUZov. Physics. -2010. - Vol.53. - No.11. -Pp. 55-59 (in Russian).

4 V. S. Yakovleva, P. M. Nagorskiy, M. S. Cherepnev. Formation of a-, b- and g-fields of the surface atmosphere by natural atmospheric radionuclides // Bulletin KRAUNZ. Phys.-mat. Science. -2014. -Vol. 1. - No. 8. - Pp. 86-96 (in Russian). 
5 M. Garcia-Talavera, A. Garcia-Perez, C. Rey, I. Ramos. Mapping radon prone areas using $\gamma$-radiation dose rate and geological information // Journal of Radiological Protection. - 2013. -Vol. 33. -No.3. - Pp. 605-20. https://doi. org/10.1088/0952-4746/33/3/605.

6 C. Sabbarese, F. Ambrosino, A. D’Onofrio, M. Pugliese, G. La Verde, V. D’Avino, V. Roca. The first radon potential map of the Campania region (southern Italy) // Applied Geochemistry. -2021. -Vol. 126. - Pp. 104890. https:// doi.org/10.1016/j.apgeochem.2021.104890

7 S. N. Manohar, H. A. J. Meijer, M. A. Herber. Radon flux maps for the Netherlands and Europe using terrestrial gamma radiation derived from soil radionuclides // Atmospheric Environment. -2013. -Vol. 81. - Pp. 399-412. https:// doi.org/10.1016/j.atmosenv.2013.09.005

8 G. Ielsch, M. E. Cushing, Ph. Combes, M. Cuney. Mapping of the geogenic radon potential in France to improve radon risk management: methodology and first application to region Bourgogne // Journal of Environmental Radioactivity. -2010. -Vol. 101. -No. 10. - Pp. 813-820. https://doi.org/10.1016/j.jenvrad.2010.04.006

9 F. Giustini, G. Ciotoli, A. Rinaldini, L.Ruggiero, M. Voltaggio. Mapping the geogenic radon potential and radon risk by using Empirical Bayesian Kriging regression: A case study from a volcanic area of central Italy // Science of The Total Environment. -2019. -Vol. 661. - Pp. 449-464. https://doi.org/10.1016/j.scitotenv.2019.01.146

10 M. E. Savkovic, V. Udovicic, D. Maletic, G. Pantelic, P. Ujic, I. Celikovic, S. Forkapic, V. Markovic, V. Arsic, J. Ilic, B. Markoski. Results of the first national indoor radon survey performed in Serbia // Journal of Radiological Protection. - 2020. -Vol. 40. -No.2. https://doi.org/10.1088/1361-6498/ab749e

11 R. J.Watson, M. A.Smethurst, G. V.Ganerod, I. Finne, A. Liv Rudjord. The use of mapped geology as a predictor of radon potential in Norway // Journal of Environmental Radioactivity. -2017. -Vol. 166. -No. 2. - Pp. 341-354. https:// doi.org/10.1016/j.jenvrad.2016.05.031

12 G. Kropat, F. Bochud, Ch. Murith, M. Palacios (Gruson), S. Baechler. Modeling of geogenic radon in Switzerland based on ordered logistic regression // Journal of Environmental Radioactivity. -2017. -Vol. 166. -No. 2. - Pp. 376-381. https://doi.org/10.1016/j.jenvrad.2016.06.007

13 R. I. Bersimbaev, O. Bulgakova. The health effects of radon and uranium on the population of Kazakhstan // Genes and Environment. -2015. -Vol. 37. -No. 18. https://doi.org/10.1186/s41021-015-0019-3

14 V. S. Yakovleva. Analysis of methods for measuring the flux density of radon and thoron from the earth's surface // Equipment and news of radiation measurements. -2010. -No. 3. -Pp. 23-30 (in Russian).

15 V. S. Yakovleva. Methods for measuring the flux density of radon and thoron from the surface of porous materials, Publishing house of the Tomsk Polytechnic University, Tomsk, 2011, 174 p. (in Russian).

16 V. I. Zherebchevsky, N. A. Maltsev. Measurement of the content of radon and thoron in samples, Publishing House BBM, Saint Petersburg, 2020, 38p. (in Russian).

17 T. I. Sisigina. Oscillations of radon exhalation from soil to atmosphere due to changes in meteorological conditions, Radioactivity of the atmosphere, soil, and fresh waters // Proceedings of the Institute of Experimental Meteorology, Moscow Department of Hydrometeorological Publishing House, Moscow, -1970. -Pp. 3-15. (in Russian).

18 V. V. Dyachkov, Z. M. Biyasheva, A. A. Komarov, Yu. A. Zaripova, A. L. Shakirov, A. V. Yushkov, O. Kh. Hamdieva, V. A. Sysoev. Experimental detection of four-day variations in radon emanation caused by the phases of the Moon // KazNU Bulletin. Physical series. -2016. - No. 1 (56) .- Pp. 120-128. (in Russian).

19 V.V. Dyachkov, S. T. Alibekov, Yu.A. Zaripova, A. V. Yushkov. Spatial and temporal patterns of radon distribution, Kazakh University Publishing House, Almaty, 2019, 101 p. (in Russian).

20 E. A. Klementyeva, S. V. Ovsyannikova, A. N. Nikitin. Dynamics of 210-Pb and 210-Po isotopes in natural meadow ecosystems and agrophytocenoses with regular application of phosphorus fertilizers // Proceedings of the National academy of sciences of Belarus. Biological series. -2017. -No. 1. -Pp. 39-47. (in Russian).

21 S. V. Druzhinin. Isotopes beryllium-7, polonium-210, lead-210 in atmospheric precipitation and aerosols in Arkhangelsk // Bulletin Pomor. university. Ser .: Natural. science. -2010. -No. 4. -Pp. 15-19. (in Russian).

22 T. Zalewska, D. Biernacik, M. Marosz. Correlations between 7Be, 210Pb, dust and PM10 concentrations in relation to meteorological conditions in northern Poland in 1998-2018 // Journal of Environmental Radioactivity. -2021. -Vol. 228. https://doi.org/10.1016/j.jenvrad.2020.106526

23 V. V. Dyachkov, Yu. A. Zaripova, A. V. Yushkov, A. L. Shakirov, M. T. Bigeldiyeva, K. S. Dyussebayeva, K. E. Abramov. Periodic variations in time of atmospheric radioactive nanoparticles // Physical sciences and technology. -2019. -Vol. 6. -No. 1-2. -Pp. 11-17. https://doi.org/10.26577/phst-2019-1-p6

24 V. V. Dyachkov, Yu. A. Zaripova, A. V. Yushkov, A. L. Shakirov, Z. M. Biyasheva, M. T. Bigeldiyeva, K. S. Dyussebayeva, K. E. Abramov. A study of the accumulation factor of the daughter products of radon decay in the surface layer using beta spectrometry // Physics of Atomic Nuclei. -2018. -Vol. 81. - Pp. 1509 - 1514. https://doi.org/10.1134/ S106377881811008X

25 G. V. Fyodorov, P. G. Kayukov, G. D. Berkinbaev. Radioecology of Kazakhstan // Materials of IV International conferences, Tomsk. -2013. - Pp. 542-545. (in Russian). 